\title{
A AVALIAÇÃO DOS CURSOS DE ENGENHARIA DE PRODUÇÃO
}

\section{THE EVALUATION OF THE COURSES OF PRODUCTION ENGINEERING}

\author{
Vanderlí Fava de Oliveira ${ }^{1}$ \\ ${ }^{1}$ UFJF; vanderli@engprod.ufjf.br
}

Recebido para publicação em: 05/03/2005 Aceito para publicação em:09/08/2005

\section{Resumo}

O objetivo deste artigo é apresentar um estudo sobre a avaliação dos cursos de Engenharia de Produção considerando os dispositivos legais vigentes e o Manual de Avaliação do INEP (Instituto Nacional de Estudos e Pesquisas Educacionais Anísio Teixeira) para esses cursos. Para isso é apresentada uma breve retrospectiva sobre a evolução desses cursos, assim como, as principais diretrizes legais e as dimensões que são avaliadas com as respectivas valorações dos aspectos que são considerados nesta avaliação. Por fim são destacadas algumas questões para reflexão na perspectiva de contribuir para o aprimoramento da avaliação desses cursos e para a afirmação de um padrão de curso de Engenharia de Produção, em acordo com o que vem sendo construído nos fóruns da ABEPRO (Associação Brasileira de Engenharia de Produção).

Palavras-chave: Avaliação de Cursos, Educação em Engenharia, Engenharia de Produção

\section{Retrospecto sobre os cursos de Engenharia de Produção}

A modalidade de curso de engenharia denominada de Engenharia de Produção é relativamente recente se comparada com as demais engenharias, especialmente a Engenharia Civil que é considerada a não militar mais antiga e que conta com mais de dois séculos de existência de cursos regulares no Brasil. O curso de engenharia considerado como o mais antigo do Brasil é o que funcionava na Real Academia de Artilharia Fortificação e Desenho do Rio de Janeiro e que foi criado em 1792, sendo o precursor em linha direta e contínua da atual Escola Politécnica da Universidade Federal do Rio de Janeiro - UFRJ (Telles, 1994).

No documento "História de Engenharia de Produção no Brasil" (1983) o autor, Professor Ruy Aguiar da Silva Leme (Faculdade de Economia e Administração - FEA/USP), mostra que a Engenharia de Produção tem sua origem no país "quando a Escola Politécnica aprovou os cursos de Engenharia de Produção e Complemento de Organização Industrial como disciplinas do curso de doutoramento (o Doutor em Engenharia existente na época)". Continua o autor afirmando que "o 
sucesso dos cursos, freqüentado por várias dezenas de engenheiros, convence a Congregação que a nova área estava sendo bastante solicitada no mercado de trabalho, fazendo com que em Maio de 1958 esta aprovasse a instalação, em nível de graduação, do curso de Engenharia de Produção como opção da Engenharia Mecânica". Ainda segundo o mesmo autor, após esta iniciativa da Poli/USP (Escola Politécnica da Universidade de São Paulo), também o ITA (Instituto Tecnológico da Aeronáutica) em 1959 e a FEI (Faculdade de Engenharia Industrial de São Bernardo do Campo/SP) em 1963, implantaram habilitações em Produção. Na UFRJ, em 1957 o curso de pós-graduação em Engenharia Econômica passou a contar com conteúdos de Produção. A partir de 1962 também a PUC-Rio (Pontifícia Universidade Católica do Rio de Janeiro) incluiu disciplinas de Produção na sua pós-graduação em Engenharia.

Do que se pode apurar, até o início da década de 70 não existiam cursos de graduação em Engenharia de Produção como modalidade. Os cursos criados até então eram de pós-graduação e os de graduação tinham a Produção como habilitação ou ênfase de outra modalidade de Engenharia, principalmente da Engenharia Mecânica. Os dois primeiros cursos de Engenharia de Produção surgiram no início da década de 70 (entre 1970 e 1972) na UFRJ e na USP de São Carlos/SP.

No final da década de 70 começaram a surgir outros cursos de Engenharia de Produção. Em 1980 já existiam 18 cursos e até 1997 criava-se aproximadamente dois cursos a cada três anos no país. A partir deste ano houve um crescimento vertiginoso do número de cursos, saltando dos 37 em funcionamento em 1997 para aproximadamente 200 cursos em 2005, registrando-se a criação em torno de quase 20 cursos por ano. Na figura 1 foram tabulados somente os cursos cujo registro foi encontrado no site do INEP (Instituto Nacional de Estudos e Pesquisas Educacionais Anísio Teixeira), no entanto, foi detectado a existência de mais 12 cursos de Engenharia de Produção via internet ou depoimentos, mas cujo registro não foi encontrado no site do INEP.

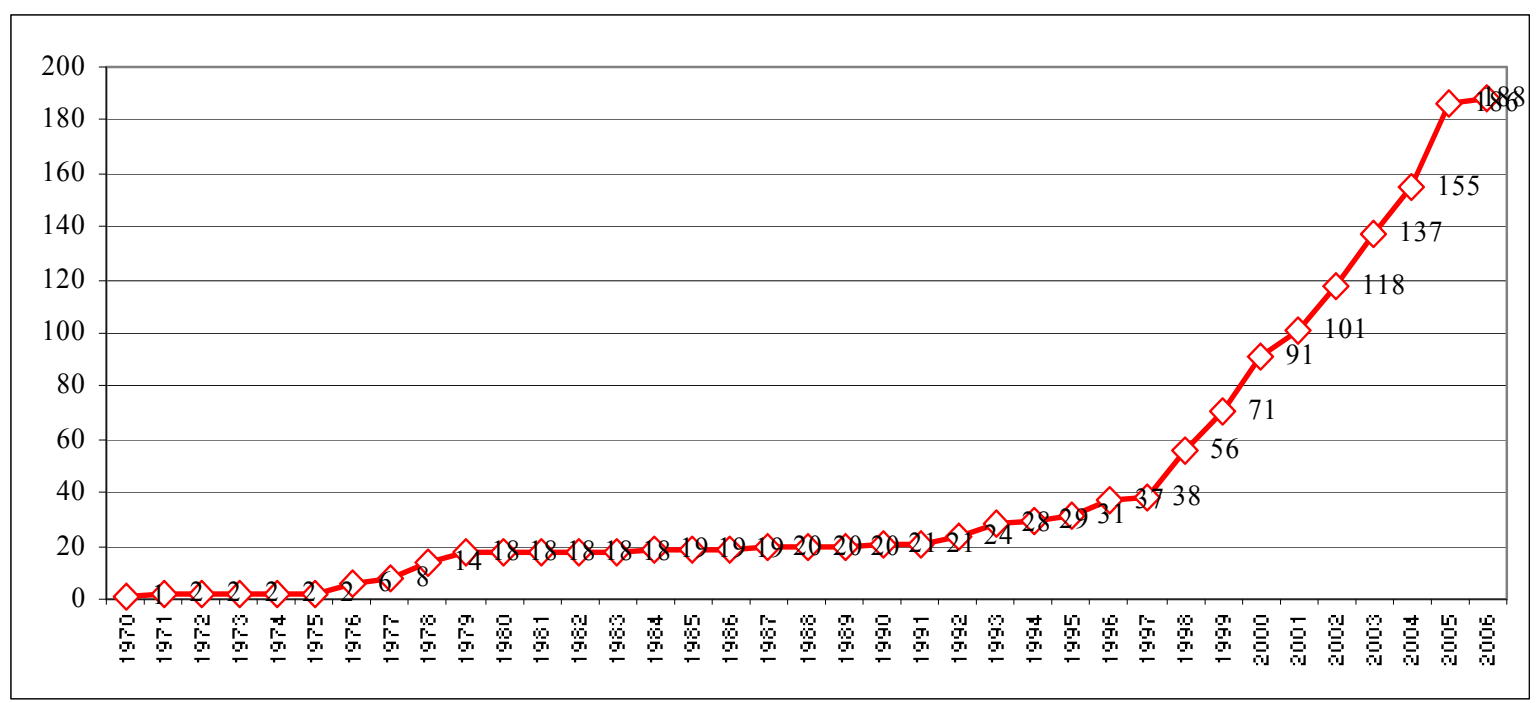

Fonte: Organizado a partir dos dados disponíveis no site do INEP (www.inep.gov.br, maio 2005)

Figura 1 - Crescimento do Número de Cursos de Engenharia de Produção no Brasil 
Um dos principais fatores que contribuem para explicar o crescimento do número de cursos de Engenharia de Produção é a própria evolução do mundo da produção conforme mostra, com bastante propriedade, a figura 02 (Cunha, 2002). As mudanças que ocorreram mais recentemente determinam que um dos capitais mais significativos das empresas na atualidade é o conhecimento, que influencia diretamente na obtenção de vantagem competitiva em processos produtivos, qualidade dos produtos e estratégia de gestão, aspectos estes que permeiam as áreas de conhecimento abrangidas pela Engenharia de Produção. Isto aliado à natureza do conhecimento de engenharia ("problem solving") torna a Engenharia de Produção aquela que melhor atende às organizações na atualidade em termos de articulação de suas funções clássicas - mercado, finanças, pessoas e produção - integrando-as ao conhecimento tecnológico e o sistêmico.

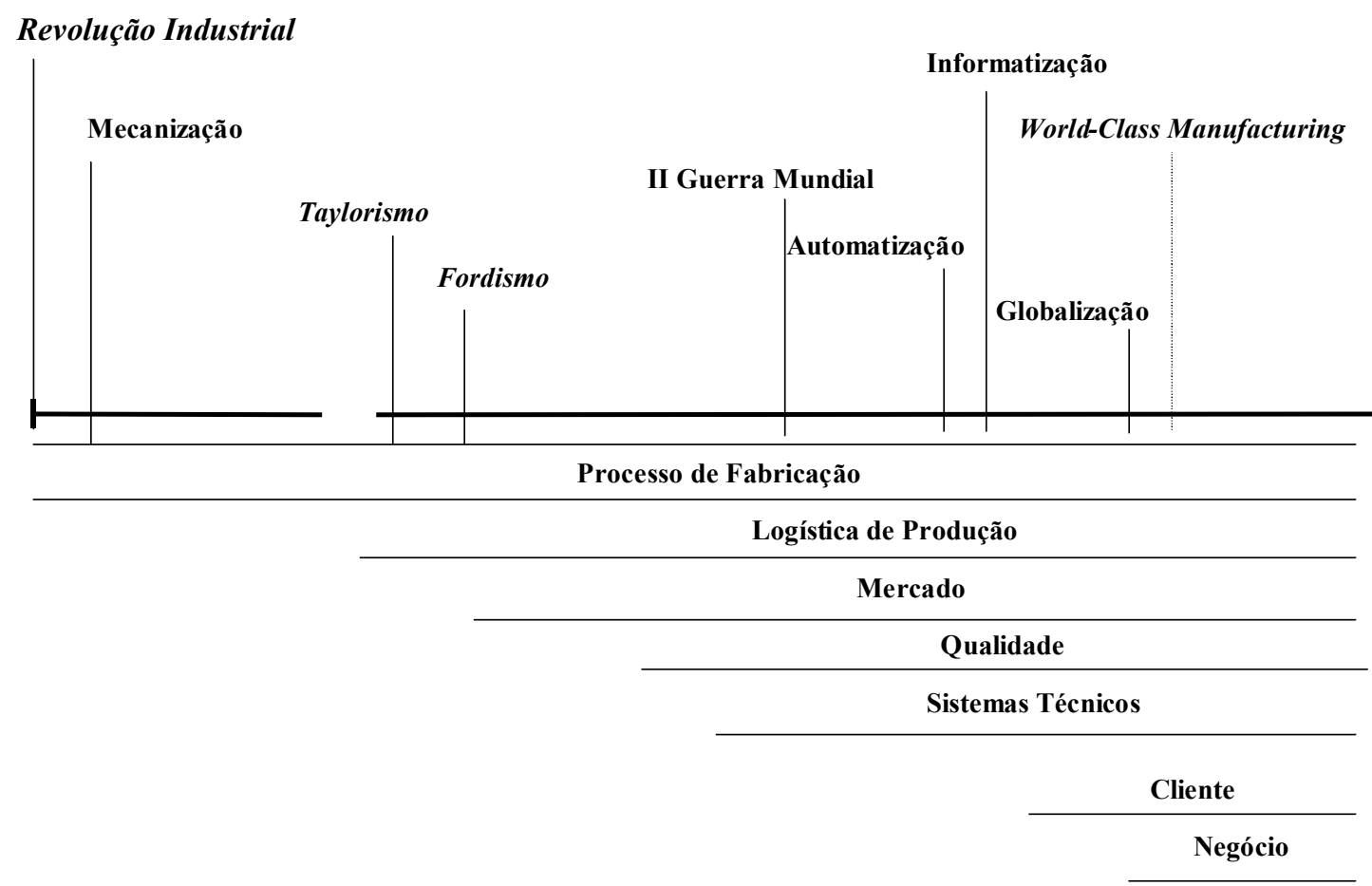

Fonte: Um Panorama da Engenharia de Produção: Raízes históricas (Cunha, 2002)

Figura 02 - Foco de atenções no mundo industrial: linha do tempo

Outra questão relevante é a mudança de foco na organização dos cursos de Engenharia de Produção. Inicialmente predominavam os cursos que tinham a Engenharia de Produção como uma ênfase dentro de uma modalidade tradicional de engenharia, como por exemplo, a Engenharia Mecânica com ênfase em Produção, o que ocorria mediante a inserção de algumas "cadeiras" de Produção no curso de Engenharia Mecânica. Na década de 90 a ênfase se inverteu, ou seja, começou a predominar os cursos com ênfase em uma base tecnológica tradicional como, por 
exemplo, Engenharia de Produção com ênfase em Mecânica. No início deste século já predominavam os chamados cursos de Engenharia de Produção "Plena".

De uma maneira geral a Engenharia de Produção vem evoluindo em acordo com as tendências verificadas nas Organizações Industriais e Empresariais. Num passado recente considerava-se que dentre os principais sustentáculos destas organizações encontravam-se as instalações e a capacidade de produção em escala (quadro 01) e, atualmente, estes pilares encontram-se mais relacionados ao conhecimento (tecnológico e sistêmico) e a capacidade destas organizações em conseguir melhoria constante dos seus produtos e processos de produção, que se traduzem nos seus principais diferenciais em termos de qualidade e produtividade.

Traçando um paralelo com o que vem ocorrendo nestas Organizações, para os cursos evoluírem não basta que se invista no aprimoramento de seus currículos e de suas instalações, há que se investir em melhorias organizacionais e de processos de ensino/aprendizagem que possam ensejar melhores métodos e meios educacionais. Neste aspecto, uma das principais questões a ser considerada é o sistema de avaliação. Através desse sistema podem ser efetivamente detectados os problemas e apontadas as propostas de melhorias, considerando-se que o sistema de avaliação não deve avaliar apenas para conferir grau ou estabelecer "rankings", mas deve avaliar para fazer progredir e implantar melhorias efetivas nos cursos.

QUADRO 01 - Evolução das Organizações e dos Cursos de Engenharia de Produção

\begin{tabular}{|c|c|c|c|}
\hline & & ANTI & ATUAL \\
\hline \multirow{3}{*}{$\begin{array}{l}\text { ORGANIZAÇÕES } \\
\text { INDUSTRIAIS E } \\
\text { EMPRESARIAIS: }\end{array}$} & $\begin{array}{l}\text { Sistemas de } \\
\text { Produção: }\end{array}$ & Rígidos & Flexiveis \\
\hline & Base Principal: & $\begin{array}{l}\text { Instalações e } \\
\text { produção em escala }\end{array}$ & $\begin{array}{r}\text { Conhecimento e } \\
\text { melhoria continua }\end{array}$ \\
\hline & Trabalhador: & $\begin{array}{l}\text { Menos treinamento } \\
\text { e conhecimento }\end{array}$ & $\begin{array}{r}\text { Mais treinamento } \\
\text { e conhecimento }\end{array}$ \\
\hline \multirow{4}{*}{$\begin{array}{l}\text { ORGANIZAÇÃO } \\
\text { DOS CURSOS }\end{array}$} & Currículos: & Rígidos & Flexiveis \\
\hline & Foco do currículo: & $\begin{array}{l}\text { Conteúdos } \\
\text { Carga Horária }\end{array}$ & $\begin{array}{r}\text { Habilidades } \\
\text { Competências }\end{array}$ \\
\hline & Aluno & Passivo & Ativo \\
\hline & $\begin{array}{l}\text { Engenharia de } \\
\text { Produção }\end{array}$ & $\begin{array}{l}\text { Parte de Outra } \\
\text { Modalidade }\end{array}$ & $\begin{array}{r}\text { Modalidade } \\
\text { de Engenharia }\end{array}$ \\
\hline
\end{tabular}

Fonte: Organizado pelo autor

\section{A avaliação dos cursos de graduação - ACG}

\subsection{Base Legal}

Em março de 2002, foi publicada a Resolução CNE/CES 11 (11/03/2002) que "institui as diretrizes curriculares nacionais do curso de graduação em Engenharia”. Em abril de 2002 foi publicada a Portaria No 990 (02/04/2002) do MEC que “estabelece as diretrizes para a organização e execução da avaliação das instituições de educação superior e das condições de ensino dos 
cursos de graduação” em acordo com o Decreto No 3.860 (9/07/2001) da Presidência da República. Ainda em 2002, o INEP coordenou a elaboração de Manuais de Avaliação dos Cursos de Graduação, selecionou e treinou os avaliadores e iniciou o processo de avaliação para reconhecimento e credenciamento dos cursos no segundo semestre de 2002 segundo estas novas diretrizes.

Até o advento dessa nova legislação, os cursos de graduação em Engenharia de Produção eram avaliados segundo parâmetros estabelecidos para os Cursos de Engenharia Mecânica, herança ainda da Resolução 78/46 ("fixa os mínimos de conteúdo e de duração do curso de graduação em Engenharia e define suas áreas de habilitações") do antigo CFE e que vigorou até a publicação da nova LDB (Lei $\mathrm{n}^{\circ}$ 9.394, de 20 /12/1996) que "estabelece as diretrizes e bases da educação nacional". Esta Resolução dividia a Engenharia em 6 grandes áreas (Civil, Minas, Materiais e Metalurgia, Elétrica, Mecânica e Química), colocando a Engenharia de Produção como uma habilitação ou ênfase da Engenharia Mecânica.

Desde 1997 a ABEPRO vinha fazendo gestões junto ao MEC para que a Engenharia de Produção se constituísse como uma grande área ou como uma modalidade no mesmo nível das demais. Nesta direção contou-se também com a participação do Professor Nivaldo Lemos Coppini (Presidente da ABEPRO 2001/2005) na "Comissão de Especialistas de Ensino de Engenharia" criada pela Portaria SESu/MEC $n^{0}$ 146/98, que elaborou a proposta que deu origem à atual CNE/CES 11/2002. Mesmo antes da publicação da Portaria № 990, a ABEPRO já havia trabalhado numa primeira proposição de Manual de Avaliação específico para a Engenharia de Produção em fevereiro de 2002, numa reunião da direção com coordenadores de cursos, realizada em Santa Bárbara D’Oeste/SP.

Ainda em abril de 2002, o Diretor de Gestão e Planejamento do INEP, Professor Tancredo Maia Filho compareceu, a convite, ao ENCEP (Encontro Nacional de Coordenadores de Engenharia de Produção), evento realizado pela ABEPRO em Manaus/AM (14 a 16/04/2002) e anunciou oficialmente que a Engenharia de Produção teria um manual próprio para avaliação e delegou àquele ENCEP a escolha dos membros da Comissão para elaboração final desse Manual ${ }^{1}$ ). Nesse mesmo ENCEP foi escolhida a Comissão composta por 7 docentes $\left({ }^{2}\right)$, posteriormente nomeados pela Portaria No 1977 (11/07/2002) do MEC que criou a "Comissão Extraordinária de Avaliação dos Cursos de Engenharia de Produção":

( $\left.{ }^{1}\right)$ O "Manual de Avaliação do Curso de Engenharia de Produção" tem o mesmo formato dos demais cursos de graduação e o que é específico de cada curso são alguns parâmetros relacionados a quantitativos. A intervenção da Comissão na elaboração do Manual foi bastante restrita e onde foi possível inserir concretamente especificidades da Engenharia de Produção foi apenas na caracterização dos laboratórios:

"Laboratórios de apoio ao ensino de conteúdos profissionalizantes gerais - Deverá ser verificada a existência de laboratórios que contemplem o ensino de conteúdos profissionalizantes da formação geral em engenharia, observando a especificidade do perfil do egresso. Deverá ser focalizada a questão da obtenção do produto através do 
processamento industrial da matéria prima, enfatizando-se o ensino de conteúdos inerentes à física desse processamento a par da sua efetiva forma de concretização".

"Laboratórios de apoio ao ensino de conteúdos profissionalizantes específicos - Deverá ser verificada a existência de laboratórios destinados ao estudo de engenharia de produtos (bens ou serviços), processos e informação. Esses laboratórios darão suporte às atividades pedagógicas destinadas ao ensino dos conteúdos profissionalizantes específicos da Engenharia de Produção, a saber: engenharia de produto, projeto de fábrica, processo produtivo, gerência de produção, qualidade, pesquisa operacional, engenharia de trabalho, estratégia e organizações e gestão econômica".

${ }^{2}$ ), Membros da Comissão Extraordinária de Avaliação dos Cursos de Engenharia de Produção: Alexandre Augusto Massote (FEI - Faculdade de Engenharia Industrial - SP) André Clementino de O. Santos (UEPA - Universidade Estadual do Pará), Antônio Sérgio Coelho (UFSC - Universidade Federal de Santa Catarina), Gilberto Dias da Cunha (UFRGS - Universidade Federal do Rio Grande do Sul e PUC/RS - Pontifícia Universidade Católica do Rio Grande do Sul), Marco Mesquita (USP - Universidade de São Paulo), Nivaldo Lemos Coppini (Presidente da ABEPRO e UNIMEP - Universidade Metodista de Piracicaba) e Vanderlí Fava de Oliveira (UFJF - Universidade Federal de Juiz de Fora).

As diretrizes curriculares (Resolução CNE/CES 11/2002) e as diretrizes de avaliação (Portaria 63/2002) trouxeram mudanças significativas para serem implantadas nos cursos de graduação em Engenharia e, em particular, para os cursos de Engenharia de Produção. Tais mudanças estão em fase de implantação e ainda não se tem um quadro claro do alcance e das conseqüências das mesmas nos cursos em termos de organização e formação profissional.

Entendendo que este sistema de avaliação necessitava alterações, o atual governo, através da Lei No 10.861 (14/04/2004) "Institui o Sistema Nacional de Avaliação da Educação Superior SINAES e dá outras providências" com o "objetivo de assegurar processo nacional de avaliação das instituições de educação superior, dos cursos de graduação e do desempenho acadêmico de seus estudantes". O SINAES aponta para a unificação dos sistemas de avaliação existentes, quais sejam: a Avaliação Institucional, a dos Cursos de Graduação (ACG) e o Exame Nacional de Cursos (ENADE) e ainda insere a auto avaliação ou a avaliação interna nas instituições.

No que se refere à ACG, num primeiro momento, o SINAES parece não alterar as atuais diretrizes pelo constante do seu artigo 4 (a seguir) que se coaduna com o que é hoje praticado:

"Art. $4^{\circ} \mathrm{A}$ avaliação dos cursos de graduação tem por objetivo identificar as condições de ensino oferecidas aos estudantes, em especial as relativas ao perfil do corpo docente, às instalações físicas e à organização didático-pedagógica.

$\S 1^{\circ}$ A avaliação dos cursos de graduação utilizará procedimentos e instrumentos diversificados, dentre os quais obrigatoriamente as visitas por comissões de especialistas das respectivas áreas do conhecimento.

$\S 2^{\circ} \mathrm{A}$ avaliação dos cursos de graduação resultará na atribuição de conceitos, ordenados em uma escala com 5 (cinco) níveis, a cada uma das dimensões e ao conjunto das dimensões avaliadas." 


\subsection{Processamento da avaliação dos cursos}

Na avaliação são verificados e pontuados cerca de 160 itens, além de emissão de parecer sobre as dimensões e as categorias avaliadas que perfazem um total de 16 . O quadro 02 apresenta a listagem das Dimensões e respectivas Categorias e Indicadores que são avaliados nos cursos. Os Aspectos que são avaliados de cada um dos Indicadores constam dos gráficos 1, 2 e 3 que estão dispostos no item 3.

QUADRO 02 - Dimensões Avaliadas nos Cursos de Engenharia de Produção

\begin{tabular}{|c|c|c|}
\hline Dimensão & Categorias & Indicadores \\
\hline \multirow{3}{*}{$\begin{array}{l}1 \text { - } \\
\text { Organização } \\
\text { Didático- } \\
\text { Pedagógica }\end{array}$} & $\begin{array}{l}\text { 1.1 Administração } \\
\text { acadêmica }\end{array}$ & $\begin{array}{l}\text { 1.1.1 Coordenação do curso } \\
\text { 1.1.2 Organização acadêmico - administrativa } \\
\text { 1.1.3 Atenção aos discentes }\end{array}$ \\
\hline & 1.2 Projeto do curso & $\begin{array}{l}\text { 1.2.1 Concepção do curso } \\
\text { 1.2.2 Currículo } \\
\text { 1.2.3 Sistema de avaliação } \\
\end{array}$ \\
\hline & $\begin{array}{l}\text { 1.3 Atividades } \\
\text { acadêmicas articuladas } \\
\text { ao ensino de graduação }\end{array}$ & $\begin{array}{l}\text { 1.3.1 Participação dos discentes nas atividades acadêmicas } \\
\text { 1.3.2 Estágio curricular supervisionado } \\
\text { 1.3.3 Trabalho final de curso }\end{array}$ \\
\hline \multirow{3}{*}{$\begin{array}{l}2 \text { - } \\
\text { Corpo } \\
\text { Docente }\end{array}$} & $\begin{array}{l}2.1 \text { Formação acadêmica } \\
\text { e profissional }\end{array}$ & $\begin{array}{l}\text { 2.1.1 Titulação Docentes com especialização na área } \\
\text { 2.1.2 Experiência profissional } \\
\text { 2.1.3 Adequação da formação }\end{array}$ \\
\hline & $\begin{array}{l}\text { 2. } 2 \text { Condições de } \\
\text { trabalho }\end{array}$ & $\begin{array}{l}\text { 2.2.1 Regime de trabalho } \\
\text { 2.2.2 Plano de carreira Ações de capacitação } \\
\text { 2.2.3 Estímulos (ou incentivos) profissionais } \\
\text { 2.2.4 Dedicação ao curso } \\
\text { 2.2.5 Relação alunos/docente } \\
\text { 2.2.6 Relação disciplinas/docente }\end{array}$ \\
\hline & $\begin{array}{l}2.3 \text { Atuação e } \\
\text { desempenho acadêmico e } \\
\text { profissional }\end{array}$ & $\begin{array}{l}\text { 2.3.1 Publicações Artigos publicados em periódicos científicos } \\
\text { 2.3.2 Produçôes intelectuais, técnicas, pedagógicas, artísticas e culturais } \\
\text { 2.3.3 Atividades relacionadas ao ensino de graduação } \\
\text { 2.3.4 Atuação nas atividades acadêmicas Atuação dos docentes em sala de aula }\end{array}$ \\
\hline \multirow{3}{*}{$\begin{array}{l}3 \text { - } \\
\text { Instalações }\end{array}$} & 3.1 Instalações gerais & $\begin{array}{l}\text { 3.1.1 Espaço físico Salas de aula } \\
\text { 3.1.2 Equipamentos Acesso a equipamentos de informática pelos docentes } \\
\text { 3.1.3 Serviços Manutenção e conservação das instalações físicas }\end{array}$ \\
\hline & 3.2 Biblioteca & $\begin{array}{l}\text { 3.2.1 Espaço físico Instalações para o acervo } \\
\text { 3.2.2 Acervo Livros Periódicos } \\
\text { 3.2.3 Serviços Horário de funcionamento }\end{array}$ \\
\hline & $\begin{array}{l}3.3 \text { Instalações e } \\
\text { laboratórios específicos }\end{array}$ & $\begin{array}{l}\text { 3.3.1 Laboratórios de apoio ao ensino de conteúdos básicos } \\
\text { 3.3.2 Laboratórios de apoio ao ensino de conteúdos profissionalizantes gerais } \\
\text { 3.3.3 Laboratórios de apoio ao ensino de conteúdos profissionalizantes específicos }\end{array}$ \\
\hline
\end{tabular}

Fonte: Manual de Avaliação do Curso de Engenharia de Produção do INEP (2002)

O processo de avaliação das condições de ensino para reconhecimento, geralmente é realizado no ano em que se dá a formatura da $1^{\mathrm{a}}$ turma, antecedendo-a para que os formandos possam ser diplomados ao término do curso (no caso do curso ser aprovado). A avaliação se inicia com a solicitação da Instituição a qual pertence o curso, encaminhada à SESU (Secretaria de Ensino Superior do MEC) através de protocolização de pedido no "Sistema de Acompanhamento de Processos das Instituições de Ensino Superior" SAPIENS que foi instituído pela Portaria do MEC $n^{\circ} 323 / 2002$ de 31/01/2002. Tudo isso é realizado via formulários eletrônicos on-line.

O pedido de avaliação é analisado pela SESU/MEC e, caso seja atendido, é aberto o Formulário Eletrônico de Avaliação para a inserção dos dados sobre o curso. Em seguida o INEP nomeia os avaliadores para analisarem a documentação e os dados inseridos pelo curso no 
Formulário e para realizarem a "avaliação in loco". A avaliação in loco constitui-se de visita de 4 dias ao curso e preenchimento do referido Formulário on-line do INEP. Após essa visita, o INEP disponibiliza o resultado da avaliação para a Instituição avaliada, havendo um prazo de 30 dias para a interposição de recursos a este resultado. Após isso, caso o curso seja reconhecido, a SESU/MEC publica uma Portaria de Reconhecimento do curso com validade especificada.

\section{Observações sobre a avaliação das condições de ensino}

Os aspectos que compõem cada indicador (quadro 02) recebem pesos de 0 a 100. Também os indicadores de cada categoria recebem pesos que somam 100 e estas, por sua vez, são ponderadas da mesma forma (de 0 a 100). Realizando-se os cálculos segundo estes pesos, pode-se estabelecer a incidência percentual de cada aspecto na avaliação de cada dimensão, conforme mostrado nos gráficos 1,2 e 3 .

\subsection{Organização do curso}

No que se refere à organização do curso (Gráfico 1), o que mais pontua é o trabalho de final de curso, por exemplo, de 5 a 6 vezes mais do que a coerência do currículo com os objetivos do curso em termos de formação.

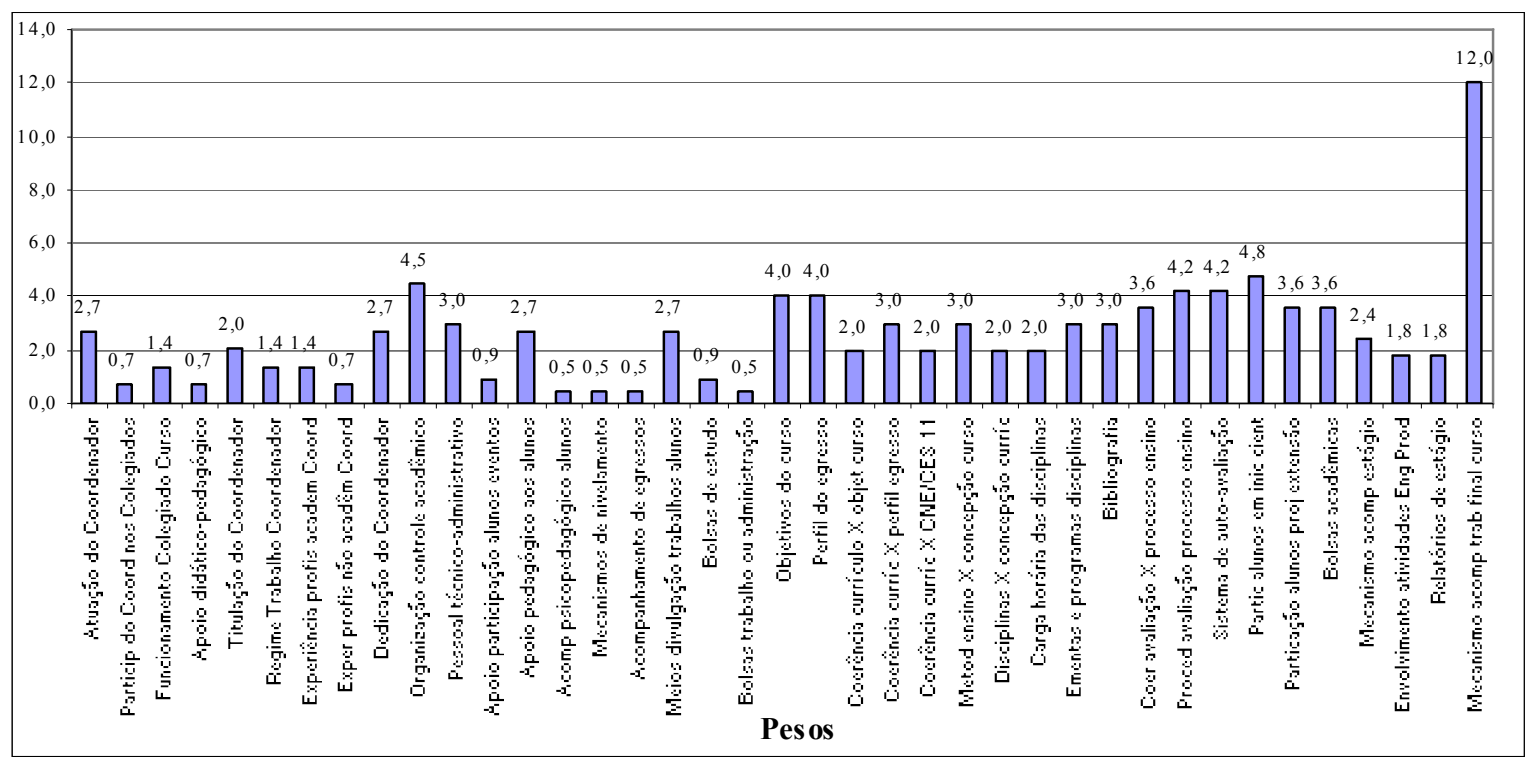

Fonte: Organizado pelo autor com base no Manual de Avaliação do Curso de Engenharia de Produção

Gráfico 01 - Pesos dos Aspectos Avaliados na Organização Didático Pedagógica 
Observe-se que, no processo de avaliação, é difícil avaliar a qualidade desses trabalhos de conclusão de curso, visto que, não há como verificar a repercussão e a aplicabilidade dos mesmos, tendo-se em vista o pouco tempo destinado à realização desta avaliação e a quantidade de itens a serem avaliados. Embora a CNE/CES 11/2002 explicite a questão relacionada aos chamados trabalhos de final de curso, pelas condições dadas para a avaliação, pode-se concluir que este aspecto fica supervalorizado na avaliação.

Outro aspecto supervalorizado é a organização acadêmica no aspecto administrativo, que pontua mais do que todos os aspectos relacionados à atenção aos discentes e, até mesmo, mais do que os objetivos do curso e o atendimento ao perfil desejado do egresso.

Dentre os aspectos subvalorizados encontra-se a "existência de apoio didático-pedagógico ou equivalente aos docentes", por exemplo, pontuando quase 20 vezes menos do que o trabalho de final de curso e 7 vezes menos do que a organização administrativa.

\subsection{Corpo docente}

$\mathrm{Na}$ avaliação da dimensão corpo docente, o que mais pesa é o tempo de magistério (Gráfico 02), que vale mais do que o dobro da titulação e a adequação do docente às disciplinas pelos quais é responsável. Esse tempo de magistério equivale, ainda, a mais de 20 vezes a atuação do docente em pesquisa. A experiência no magistério é importante, mas o que é contabilizado é apenas o tempo, sem levar em conta se o docente realmente evoluiu academicamente durante o tempo contabilizado. Exemplificando, esse tempo de magistério pontua 5 vezes mais que a formação pedagógica do docente.

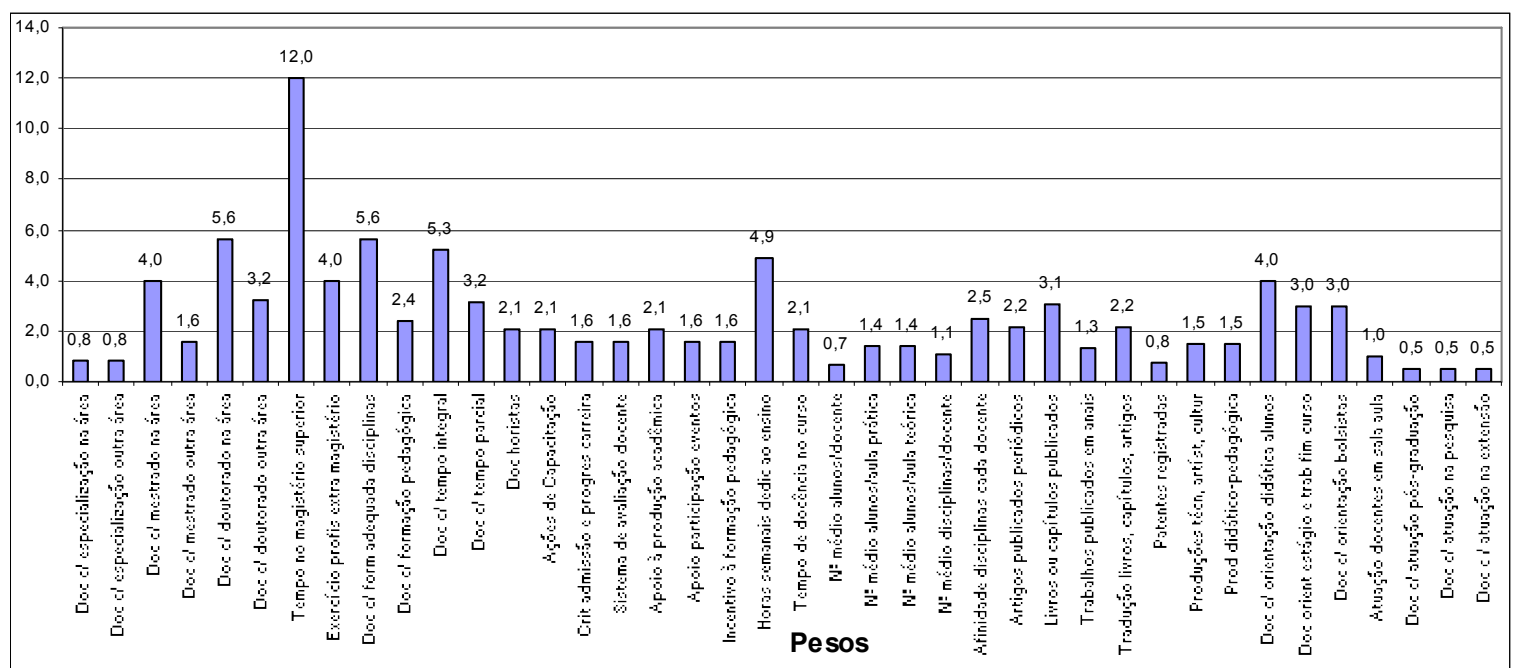

Fonte: Organizado pelo autor com base no Manual de Avaliação do Curso de Engenharia de Produção

Gráfico 02 - Pesos dos Aspectos Avaliados no Corpo Docente 
Em termos de aspectos subvalorizados estão os critérios de admissão e de progressão na carreira que pontuam pouco na avaliação, por exemplo, oito vezes menos que o tempo de magistério. Também o incentivo à formação pedagógica dos docentes não é adequadamente valorizado, principalmente se for considerado que este aspecto é fundamental para a melhoria dos processos de ensino/aprendizagem.

Os aspectos menos valorizados dessa dimensão são os relacionados à participação dos docentes em pesquisa, extensão e pós-graduação o que acaba sendo um contra-senso, pois o envolvimento nestas atividades é a melhor oportunidade para os docentes se manterem atualizados. No caso específico da Engenharia de Produção, na qual o conhecimento relacionado às suas subáreas está sendo constantemente atualizado, isto pode significar, inclusive, não atender aos objetivos traçados para o curso.

\subsection{Instalações}

Dentre as dimensões a que apresenta menos disparidades é a relacionada à avaliação das instalações, na qual a biblioteca e os laboratórios são os itens mais valorizados. No que se refere à biblioteca, o aspecto que mais pontua é o relacionado aos livros e nos laboratórios é mais valorizado o aspecto relacionado às condições de funcionamento destes.

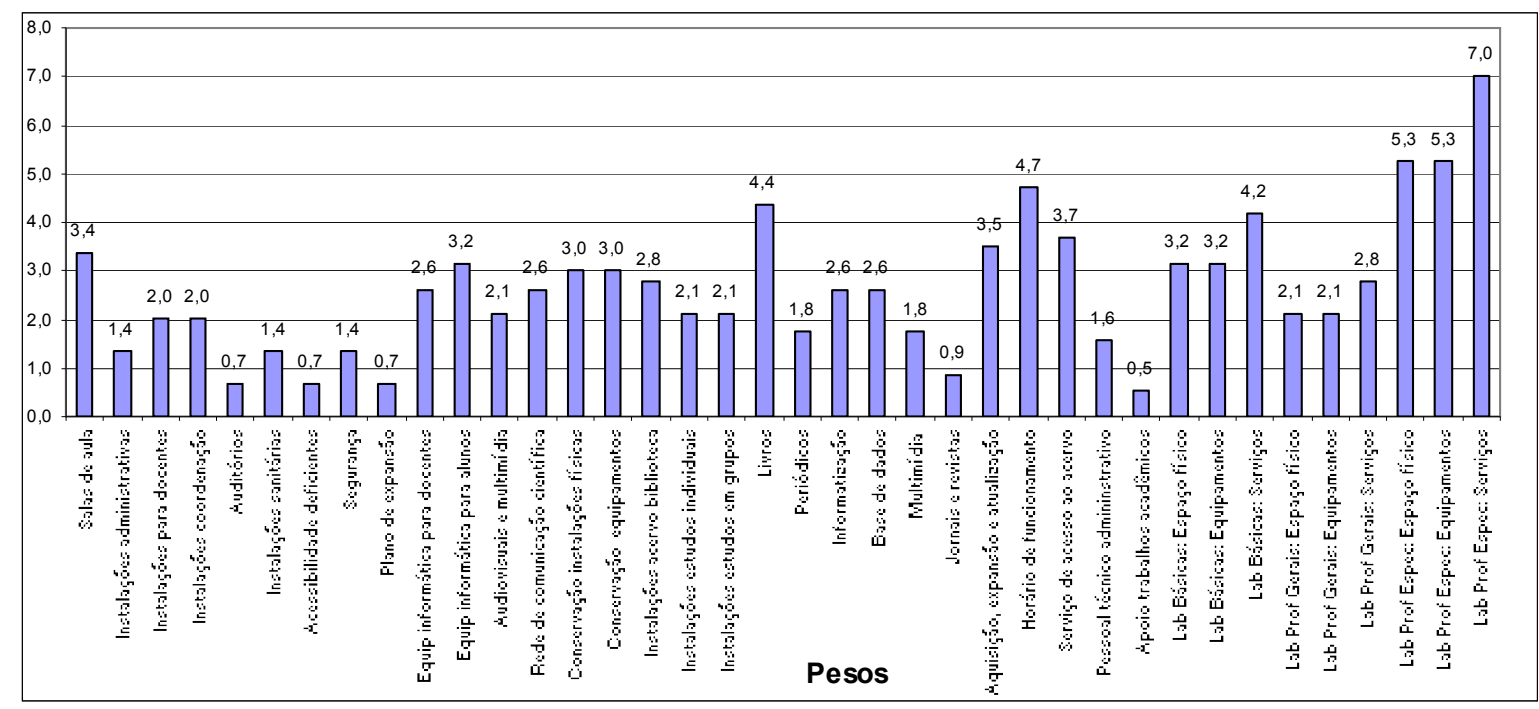

Fonte: Organizado pelo autor com base no Manual de Avaliação do Curso de Engenharia de Produção

Gráfico 03 - Pesos dos Aspectos Avaliados nas Instalações

Em termos gerais ainda há que se observar que, tendo-se em vista que o sistema se baseia principalmente na nota final calculada pelo Formulário Eletrônico, mesmo que o curso não disponha de elementos vitais para o seu adequado funcionamento, como currículo coerente ou infraestrutura adequada, entre outras, o mesmo pode obter nota suficiente para sua aprovação e reconhecimento. 


\title{
4. Considerações finais
}

O sistema atual de avaliação, que é realizado pelo INEP, está completando dois anos e já se dispõe de material suficiente para que sejam estudados os seus diversos aspectos, permitindo identificar as falhas porventura existentes, assim como, elaborar propostas de aprimoramento e de melhorias. Há que se levar ainda em conta que, com o advento do SINAES, alguns aspectos devem ser alterados para melhor adequação ao mesmo em termos de integração com as outras avaliações que serão realizadas.

Este breve estudo identifica algumas questões na pontuação de aspectos que são avaliados nos cursos que merecem uma reflexão sobre os seus efeitos, principalmente, se o pretendido é que a avaliação seja para, entre outros, corrigir falhas e melhorar o curso. Deve-se ter em mente que há a necessidade de cursos estruturados de forma que "todos se formem com uma instrução não aparente, mas verdadeira, não superficial, mas sólida" como já alertava Comenius na sua Didactica Magna (1657) no capítulo “As Escolas podem ser Reformadas”. Com certeza, reformar sem um sistema de avaliação consistente pode perpetuar a sensação de que o escrito por Comenius continua sempre atual.

Mais do que apresentar dados iniciais, com este estudo, o autor gostaria de convidar os envolvidos com a Engenharia de Produção a refletirem sobre esse sistema de avaliação, tendo como um dos objetivos principais, a construção de um padrão para os cursos dessa modalidade de engenharia. A figura 1 mostra que tem havido um aumento vertiginoso de cursos de Engenharia de Produção nos últimos 8 anos e que, caso não se tome os devidos cuidados, pode ocorrer um processo no qual se verifica um crescimento quantitativo que perde de vista a questão da qualidade. Nesta direção é importante reafirmar os fóruns da ABEPRO como aqueles privilegiados para o travamento destas discussões no sentido de se garantir um padrão de qualidade para os cursos de Engenharia de Produção no país.

\begin{abstract}
The objective of this paper is to present a study concerning the evaluation of the courses of Engineering of Production considering the effective legal devices and the Manual of Evaluation of the INEP (National Institute of Studies and Educational Research Anísio Teixeira) for these courses. For this, one brief retrospect concerning the evolution of these courses, as well as, the main legal lines of direction and the dimensions is presented that are evaluated with the respective valuations of the aspects that are considered in this evaluation. Finally some questions for reflection in the perspective are detached to contribute for the improvement of the evaluation of this course and for the affirmation of a standard of course of Engineering of Production, in agreement with what it comes being constructed in forums of the ABEPRO (Brazilian Association of Engineering of Production).
\end{abstract}

Key words: Evaluation of Courses, Engineering Education, Engineering of Production 


\section{Referências}

ASSOCIAÇÃO BRASILEIRA DE ENGENHARIA DE PRODUÇÃO. Disponível em: http://www.abepro.org.br. Acesso em: 2004.

COMENIUS, I. A. (1621/1657) - Didactica Magna. Trad Joaquim Ferreira Gomes, versão para eBook, Fundação Calouste Gulbenkian, 2001. Disponível em http://eBooks.com. Acesso em: 2004.

CUNHA, Gilberto Dias. Um panorama da engenharia de produção. [S.1.]: ABEPRO. Disponível em: http://www.abepro.org.br. Acesso em: 2002.

INSTITUTO NACIONAL DE ESTUDOS E PESQUISAS EDUCACIONAIS. Disponível em: http://www.inep.gov.br. Acesso em: 2004.

LEME, Ruy A. S. História de Engenharia de Produção no Brasil. 1983. (mimeo).

OLIVEIRA, V. F. Um estudo sobre a avaliação dos cursos de engenharia de produção. In: ENCONTRO NACIONAL DE ENGENHARIA DE PRODUÇÃO, 21., 2004, Florianópolis. Anais... Florianópolis: ABEPRO, 2004. 1 CD-ROM.

OLIVEIRA, Vanderlí F. Teoria, prática e contexto no curso de Engenharia. In: PINTO, D. P.; NASCIMENTO, J. L. (Orgs.). Educação em Engenharia: metodologia. São Paulo: [s.n.], 2002. v. 1. p. 1-296.

PINTO, D. P.; OlIVEIRA, V. F.; PORTElA, J. C. S.; DUQUE, C. A. As discussões sobre o Projeto Político Pedagógico na Faculdade de Engenharia da UFJF. ENGEVISTA, Niterói, v. 5, n. 9, p. 31-40, 2003.

PINTO, D. P.; PORTELA, J. C. S.; OLIVEIRA, V. F. Diretrizes curriculares e mudança de foco no curso de Engenharia. In: COBENGE, 2003, Rio de Janeiro. Anais... Rio de Janeiro: ABENGE, 2003. v. 1, p. 1-9.

TELLES, P. C. S. História da Engenharia no Brasil: século XX. 2. ed. Rio de Janeiro: Clavero, 1994.

TELLES, P. C. S. História da Engenharia no Brasil: séculos XVI a XIX. 2. ed. Rio de Janeiro: Clavero, 1994.

UNIVERSIDADE FEDERAL DO RIO GRANDE DO SUL. Curso de Engenharia de Produção. Disponível em: http://www.producao.ufrgs.br/graduacao/curso.asp. Acesso em: 2004. 